\title{
A enfermagem e suas apostas no autocuidado: investimentos emancipatórios ou práticas de sujeição?
}

\author{
Nursing and its reliance on self-care: emancipatory investments or practices of submission?
}

La enfermería y sus apuestas en el autocuidado: ¿ inversiones emancipatórias o prácticas de sujeción?

\section{Dora Lúcia Liedens Corrêa de Oliveiral}

'Universidade Federal do Rio Grande do Sul. Escola de Enfermagem. Porto Alegre, RS

Submissão: 08/09/2009

Aprovação: $17 / 10 / 2010$

\section{RESUMO}

O artigo objetivou refletir sobre a prevalência do autocuidado como um possível e desejável resultado dos empreendimentos educativos da enfermagem com vistas à autonomia para o cuidado de si. Argumenta-se que, neste contexto, o ensino para o autocuidado tem sido encaminhado segundo orientações técnicas e definições tendenciosas do Que seja "ter saúde", do Que significa "ser autônomo" e dos sentidos de "cuidar-se". Neste sentido, fazendo uso de algumas premissas da promoção da saúde, Questiona-se o potencial libertador e de promoção de autonomia deste ensino, indicando como dúvida se este não seria mais um investimento na submissão dos sujeitos do Que uma ação promotora de emancipação. Conclui-se propondo a escuta como alternativa para a minimização dos dilemas produzidos neste contexto.

Descritores: Enfermagem; Autocuidado; Autonomia pessoal; Educação em saúde.

\section{ABSTRACT}

The paper aimed at reflecting on the prevalence of self-care as a possible and desirable result of nursing education enterprises which focus on individual autonomy for one's own care. It can be argued that, in such a context, the teaching toward self-care has been directed according to technical orientations and biased definitions of "being healthy", of what it means to "be autonomous" and the meanings of "taking care of oneself". In this sense, taking into account the premises of health promotion, one Questions the potential for self-care teaching to be liberating and to promote autonomy. One asks whether this could be more of a case of yet another investment on the submission of subjects than an action that promotes emancipation. The conclusion proposes "listening" as an alternative for minimizing the dilemmas produced in this context.

Key words: Nursing; Self-care; Personal autonomy; Health education.

\section{RESUMEN}

El artículo tiene el objetivo de reflexionar acerca de la prevalencia del autocuidado como un posible y deseable resultado de los emprendimientos educativos de la enfermería con vistas a la autonomía para el cuidado de sí. Se argumenta Que, en este contexto, la enseñanza para el autocuidado ha sido encaminado según orientaciones técnicas y definiciones tendenciosas de lo Que sea "tener salud", de lo Que significa "ser autónomo" y de los sentidos de "cuidarse". En este sentido, haciendo uso de algunas premisas de la promoción de la salud, se cuestiona el potencial libertador y de promoción de autonomía de esta enseñanza, indicando como duda si no sería esta una inversión más en la sumisión de los sujetos Que una acción promotora de emancipación. Se concluye proponiendo la escucha como alternativa para la minimización de los dilemas producidos en este contexto.

Descriptores: Enfermería; Autocuidado; Autonomía personal; Educación en salud.

AUTOR Dora Lúcia Liedens Corrêa de Oliveira. Rua Sarmento Leite, 245. CEP 90050-170. Porto Alegre, RS.

CORRESPONDENTEＥ-mail: dora@enf.ufrgrs.br 


\section{INTRODUÇÃO}

O objetivo deste artigo é compartilhar com os leitores da REBEn algumas reflexões sobre o viés libertário Que tem permeado o trabalho da enfermagem na promoção da autonomia daqueles Que são sujeitos de suas ações de cuidado. Antes de começar Quero declarar de que lugar eu falo Quando levanto Questões acerca deste tema. Sou enfermeira, docente em um curso de graduação e pósgraduação em enfermagem, com Mestrado em Educação e Doutorado em Educação em Saúde. Por consequência tenho me dedicado na academia a estudar a temática da promoção da saúde e da educação em saúde, esta última nas suas dimensões técnicoformativas (formação inicial, continuada e mais recentemente educação permanente em saúde) e também naQuelas mais imediatamente associadas ao cuidado em saúde. Estes espaços têm me oferecido oportunidades para desenvolver um posicionamento crítico a respeito dos saberes Que aprendi como verdades no curso de graduação em enfermagem, em particular aQueles sobre a viabilidade de um dos principais e mais tradicionais projetos da enfermagem, a promoção do autocuidado.

Dada a inevitável associação entre "autocuidado" e "autonomia", e a relevância destes dois constructos para a enfermagem e, num sentido mais global, para a organização da vida na contemporaneidade, penso ser pertinente encaminhar uma discussão acerca destas duas temáticas, Que permanecem bem atuais, apesar de estarem relacionadas à prática da enfermagem há muito tempo.

Autonomia vem do grego - auto, Que Quer dizer "próprio" ou "para si mesmo" e nomos, Que Quer dizer "lei" ou "norma". Assim, autonomia seria a capacidade do indivíduo para definir suas próprias regras e limites, opondo-se à heteronomia, Que indica o estado daquele ou daquilo que é regrado, determinado por outro(1).

Desde o início da sua história o movimento da promoção da saúde vem articulando seus projetos promocionais a partir de investimentos na autonomia dos sujeitos para o cuidado de si. Como destacam os documentos oficiais, a essência da promoção da saúde é a autonomia ${ }^{(2)}$, o Que sugere certa simbiose entre os significados de saúde e de autonomia. Para o projeto da promoção da saúde é central preparar/capacitar os indivíduos para o cuidado de si, o Que deve acontecer por intermédio de ações educativas. A educação é, assim, indicada como a estratégia de excelência para a promoção da saúde da população, saúde viabilizada a partir da autonomia para o autocuidado.

Apesar de parecer uma proposta tradicional e bastante familiar para Quem trabalha no campo da saúde - esta tarefa de educar o público para capacitá-lo a se responsabilizar por sua saúde -, o projeto da promoção da saúde se propõe a inovar. A inovação estaria centrada nas seguintes premissas: (1) a saúde não pode mais ser entendida reduzidamente como ausência de doença, mas como Qualidade de vida e um recurso para a vida; (2) a saúde é resultado de múltiplos fatores, inclusive ambientais; (3) ações promocionais em saúde devem investir paralelamente em mudanças de estilo de vida - dimensão individual, e em mudanças contextuais - dimensão estrutural; (4) a educação pode promover saúde, mas o foco não deve ser apenas informar, mas, também, aumentar a consciência crítica dos sujeitos sobre sua realidade para Que possam nela intervir para melhorá-la e, (5) nos empreendimentos educativos devem ser privilegiados espaços dialógicos de aprendizagem, evitando-se metodologias de persuasão(3).

O paradoxo apresentado aos profissionais de saúde a partir dessas premissas é: como promover a autonomia dos sujeitos, sem abandonar os saberes aprendidos na formação sobre o Que é saúde, sobre o Que fazer para evitar a perda da saúde e como fazer para recuperá-la? Como referido na literatura(4) , "se aceitamos autonomia como principal objetivo da educação somos forçados a concordar Que se pessoas educadas escolherem agir de forma não saudável, e desde Que isto não interfira na liberdade dos outros, isto é um resultado aceitável do processo educacional."

Neste sentido é possível argumentar Que a óbvia hegemonia de profissionais com formação em saúde no campo da promoção da saúde é determinante dos cenários promocionais, aí incluídos os saberes, as práticas e as intencionalidades destas práticas. Por mais Que se pretenda inovar no campo da promoção da saúde, fica complicado garantir a implementação das novas propostas, sem investir em mudanças na formação.

Os conflitos são inicialmente conceituais. Como compatibilizar as tradicionais concepções sobre o Que seja saúde Que permeiam a formação, ainda focada nos saberes sobre doenças, e os objetivos inovadores da promoção da saúde, propostos na direção da melhoria da Qualidade de vida? Como educar indivíduos para a saúde sem orientar o processo educativo para a comunicação de saberes Que, apesar de selecionados em espaços externos à vida cotidiana desses sujeitos, devem funcionar justamente como instrumentos cotidianos para a manutenção dessa vida?

\section{A EDUCAÇÃO PARA O AUTOCUIDADO - EMANCIPAÇÃO OU SUJEIÇÃO?}

No contexto da educação em saúde, onde o foco é o autocuidado, praticamente nada mudou a partir das inovações propostas pelo movimento da promoção da saúde e do Que se convencionou chamar de "nova saúde pública", assim denominada para enfatizar as transformações introduzidas no campo pela promoção da saúde. Apesar dos avanços propostos, a educação em saúde, campo em Que a enfermagem tem uma grande inserção, permanece geralmente centrada em práticas educativas autoritárias e em saberes unilateralmente selecionados como necessários, a partir de critérios técnicos.

Neste cenário, ensinar saúde com vistas ao autocuidado tem implicado a imposição de estilos de vida estabelecidos desde o ponto de vista dos profissionais da saúde, como saudáveis. Os imperativos constituídos a partir da definição técnica do Que seja um estilo de vida compatível com saúde são, contudo, apresentados aos sujeitos como escolhas possíveis, não obrigatórias, seguindose a lógica da escolha informada. Fornecemos informações sobre saúde para Que os indivíduos possam realizar suas escolhas, cientes dos prós e contras de determinadas opções, mas a escolha é, em princípio ou por princípio, livre. Ironicamente, este movimento na direção da promoção da autonomia individual via escolha informada acaba reduzindo muito as possibilidades da independência pretendida, porque emerge carregado de "verdades" da ciência, a Qual é difícil contrariar.

O Que é interessante nisto tudo é Que, a partir do movimento da promoção da saúde, o Que antes era alvo de críticas, destacandose aí o potencial de sujeição de modelagens de educação em saúde 
Que não reconheciam, nem valorizavam, a autonomia dos indivíduos, passou a ser aceito, sob o pretexto de Que a promoção da "livre escolha" vinha ao encontro dos ideais democráticos da sociedade contemporânea. Poder levar a vida de acordo com escolhas pessoais significaria, neste contexto, assumir responsabilidades perante a sociedade e ter legitimado um status de cidadania.

A insistente prevalência do autocuidado como um possível e desejável resultado dos empreendimentos educativos em saúde, muitas vezes desenvolvidos no âmbito da enfermagem, guarda relação com a ideologia do individualismo, onde é central a noção de autonomia individual. A forte influência desta ideologia no campo da saúde tem pelo menos duas origens: a formação em saúde ainda fortemente impregnada pelo paradigma biomédico, e, assim, pouco porosa a compreensões socioantropológicas acerca da saúde e da não saúde; e na racionalidade política Que predomina na atualidade, a Qual é definidora do neoliberalismo como regime hegemônico. No primeiro caso, um problema importante, é Que a formação é fundamentada em teorias cognitivo-comportamentalistas Que configuram processos de aprendizagem focados na transmissão de informações e mudanças de atitudes. Não raro, esta formação negligencia os determinantes sociais e culturais da saúde, individualizando os processos de adoecimento.

Deste modo, não é de estranhar Que os profissionais da saúde, formados neste contexto, apostem tudo na promoção da saúde do "outro" a partir de ações verticalizadas, com pouco espaço para a escuta e impregnadas daQueles saberes definidos pela ciência como de inequívoca importância para o cuidado de si. No segundo caso, a influência do neoliberalismo na definição da noção de autogoverno como um ideal a ser perseguido, tem a ver com a ideia de Que o Estado não pode intervir na vida privada das pessoas, pois elas têm o direito de organizarem suas vidas segundo suas próprias escolhas. Várias responsabilidades individuais resultam daí, entre as Quais, a de manter-se saudável, resistindo às inúmeras tentações e riscos de desvios de comportamento Que a vida diária oferece $\mathrm{e}^{(5)}$.

Vivemos num clima em Que estar bem se tornou uma obrigação e, num meio em Que viver é estar cada vez mais em estado de risco, o "estar bem" é percebido como uma possibilidade que depende do cuidado que se tenha consigo mesmo. Não é por acaso, portanto, Que o domínio de si, representado pelo autocuidado, se tornou um pré-requisito para a saúde na contemporaneidade ${ }^{(3)}$.

Nos espaços de ensino do autocuidado perdem-se, muitas vezes, oportunidades de diálogo com o outro, desprezando-se seus saberes e experiências. O sujeito da aprendizagem pretendida fica, assim, posicionado como um outro Que pouco ou nada sabe sobre o viver saudável, sobre como agir perante os perigos da vida diária, sobre a importância, para viver bem, de certas capacidades físicas, em detrimento de outras, sobre como manter-se saudável, etc. O ensino para o autocuidado e a pretendida autonomia para o cuidado de si Que deveria resultar da prática educativa em saúde são encaminhados segundo orientações técnicas e definições tendenciosas do que seja "ter saúde", do Que significa "ser autônomo" e dos sentidos de "cuidar-se". Tomando-se este ensino em saúde como prática de cuidado, pergunta-se: seria esta uma prática libertadora, de promoção da autonomia dos sujeitos? Ou seria ela um investimento consciente na submissão desses sujeitos?

Considerando-se a premissa de que a saúde é um fenômeno social, argumento do Qual, provavelmente, ninguém mais discorda,
Qual o grau de possível sucesso de projetos unilaterais, individualizados e descontextualizados dirigidos ao ensino de competências para o cuidado de si? Tomemos como exemplos as nossas próprias experiências de autocuidado, invariavelmente limitadas por elementos do contexto Que são mais ou menos controláveis por nós, independentemente dos nossos saberes sobre saúde e da nossa vontade de agir em conformidade com estes saberes. Ainda neste sentido, a premissa de Que é possível sermos autônomos para cuidarmos de nós mesmos é problemática mesmo em situações em Que conseguimos manter certo controle sobre o modo de andar da vida, ajustando nossos estilos de viver a partir do Que já aprendemos sobre saúde. Seguir os discursos da saúde e adotar os padrões de comportamento neles ditados como "os mais corretos" pode ser considerado como situação de evidente autonomia?

Quero ainda chamar a atenção para uma Questão relevante para a discussão Que estou tentando encaminhar. Este campo do cuidado voltado especificamente ao cuidado de si e à autonomia individual, central na organização da vida nas sociedades ocidentais contemporâneas, tem sido atravessado por discursos de risco, os Quais são extremamente eloquentes. Legitimados por abordagens técnico-científicas baseadas em avaliações Quantitativas e cálculos epidemiológicos, os discursos sobre risco em saúde têm sido usados cotidianamente pelos profissionais da saúde, nas suas investidas para a promoção de mudanças de comportamento em prol da saúde ${ }^{(6)}$. A noção de risco incorpora neste contexto sentidos coerentes com as abordagens mais tradicionais da saúde pública, uma vez Que assume o pressuposto de Que situações onde há probabilidade de danos à saúde das pessoas são, com exceção daQuelas resultantes de fenômenos naturais imprevisíveis, conseQuência do mau comportamento dos indivíduos ${ }^{(6)}$. Como argumentam os sociólogos, risco tem sido definido no campo da saúde como um problema centrado na pessoa, com um óbvio efeito na produção de identidades e formas de governo ${ }^{(6,7)}$. Desde essa perspectiva, somos guardiões da nossa própria saúde, protegendo-nos contra os riscos, o Que resulta na necessidade de uma vigilância redobrada. Monitorados externa e internamente, tornamo-nos não apenas alvo da vigilância dos profissionais da saúde, mas, também, foco de mecanismos de controle acionados por nós mesmos. Esta reflexão expõe como a retórica sobre a associação entre autonomia e autocuidado se fortalece através dos discursos de risco.

Argumenta-se na literatura sociológica sobre risco Que esse discurso de autogoverno, Que é incorporado a concepções de "risco em saúde", tem um grande impacto na produção de novos contornos para o "self" (7), o Que aumenta as responsabilidades dos profissionais da saúde, aí incluídos os da enfermagem, enQuanto produtores e comunicadores desses discursos. Na contempo-raneidade, a noção de risco está diretamente associada à biografia do indivíduo, significando o caminho entre o Que somos e o que podemos nos tornar a partir das nossas escolhas pessoais e não das circunstâncias objetivas Que constituem a nossa vida. Neste contexto, o risco não é considerado como externo ao "self" como era no passado (o risco de ser invadido por um vírus ou prejudicado pela poluição), mas localizado no interior do "self". A AIDS é um exemplo emblemático, Que pode ilustrar o Que estou tentando argumentar. Neste caso, provavelmente o próprio vírus HIV já não tenha tanta importância enquanto risco à saúde. $\mathrm{O}$ maior risco talvez esteja na capacidade do indivíduo para controlar o seu comportamento sexual( ${ }^{(6)}$. 


\section{E A APOSTA DA ENFERMAGEM NA AUTONOMIA PARA O AUTOCUIDADO? HÁ LUZ NO FIM DO TÚNEL?}

As considerações desenvolvidas até aQui apontam para certo pessimismo com relação à possibilidade de um conteúdo de autonomia nos empreendimentos educativos da enfermagem dirigidos à promoção do autocuidado, os Quais, na minha maneira de ver, apesar dos avanços na retórica da saúde, permanecem embasados em concepções reduzidas de saúde e focados equivocadamente apenas em mudanças individuais de comportamento. A inevitável "enformação" (no sentido de colocar os indivíduos em uma forma) Que os imperativos da saúde produzem através da uniformização de padrões de comportamento para aproximá-los, o mais possível, de parâmetros de desejável salubridade, alimenta este pessimismo.

Minhas desconfianças com relação ao sucesso da promoção do autocuidado como investimento na autonomia dos sujeitos e, finalmente na promoção da sua saúde, contudo, me estimulam a pensar alternativas para a superação dos conflitos Que identifico no espaço em Que me movimento como enfermeira e educadora em saúde.

Uma possível saída talvez seja a priorização da escuta no nosso cotidiano de trabalho: escuta do outro, Que é o sujeito do nosso cuidado (na reflexão Que faço aqui, 'cuidado' representado pela prática da educação em saúde) e escuta do próprio 'eu', no sentido da produção de um projeto de cuidado Que seja reflexivo (ao contrário de práticas realizadas no "piloto automático", definidas a partir de prescrições e verdades descontextualizadas e autoritariamente impostas $)^{(8)}$. A aposta é Que a escuta do outro possa nos tornar conhecedores e sensíveis aos seus desejos, aproveitando neste ato a oportunidade de trocar posição com este outro a partir do reconhecimento de Que nele há certa projeção de nós mesmos. Afinal, atirem a primeira pedra, aQueles entre nós Que, em algum momento da vida, já não desfrutaram os prazeres garantidos pela desobediência à tirania dos discursos da saúde.

Nesse processo de escuta, ouvir a nós mesmos poderá ser revelador de euanto as nossas práticas de cuidado tendem a se distanciar dos nossos desejos mais conscientes. A partir desse encontro entre o 'eu', cuidador, e o 'outro', sujeito do cuidado, poderão ser construídos, de forma compartilhada, projetos de cuidado orientados na direção de interesses comuns( ${ }^{(9)}$. Quem sabe a partir daí, se possa começar a pensar na possibilidade de um cuidado promotor da autonomia dos sujeitos, não num sentido paternalista - alguém outorgando autonomia a um outro-, nem num sentido unilateral e absoluto- a garantia do livre arbítrio ao sujeito do cuidado - mas uma autonomia regulada pelo próprio sentido ético do encontro Que, no meu entender, configura o ato de cuidar - a ética da responsabilidade mútua para com os projetos de felicidade do outro(10).

\section{REFERÊNCIAS}

1. Eirado A, Passos E. A noção de autonomia e a dimensão do virtual. Psicol Estudo 2004; 9(1): 77-85.

2. World Health Organization. The Ottawa Charter For Health Promotion. Geneve: WHO; 1986.

3. Oliveira DLLC. A nova saúde pública e a promoção da saúde via educação: entre a tradição e a inovação. Rev Latino-am Enfermagem 2005; 13(3): 423-31.

4. Weare K. The contribution of education to health promotion. In: Bunton R, Macdonald G, editors. Health Promotion: disciplines and diversity. London: Routledge \& Kegan Paul; 1995.

5. Castiel LD, Diaz CAD. A Saúde Persecutória: os limites da responsabilidade. Rio de Janeiro: Editora Fiocruz; 2007.

6. Oliveira DLLC. Brazilian adolescent women talk about HIV/

AIDS risk: reconceptualizing risk sex - What implications for health promotion? [thesis]. London: Institute of Education, University of London; 2001 .

7. Petersen A, Lupton D. The new public health: health and self in the age of risk. London: Sage; 1997.

8. Coelho EAC, Fonseca RMGS. Pensando o cuidado na relação dialética entre sujeitos sociais. Rev Bras Enferm 2005; 58(2): 2 14-7.

9. Hames MLC, Carraro TE, Ramos FR, Tholl AD. A alteridade como critério para cuidar e educar nutrizes: reflexões filosóficas da prática. Rev Bras Enferm 2008; 6 I (2): 249-53.

10. Ayres IR. Norma e formação: horizontes filosóficos para as práticas de avaliação no contexto da promoção da saúde. Ciên Saúde Coletiva 2004; 9(3): 583-92. 